\title{
PENGARUH SEPEDA MOTOR TERHADAP KAPASITAS BAGIAN JALINAN PADA PERENCANAAN BUNDARAN DI SIMPANG TUJUH ULEE KARENG
}

\author{
Sugiarto Sugiarto $^{1)}$, Ruhdi Faisal ${ }^{2}$, Mohammad Reyhan ${ }^{3)}$ \\ ${ }^{1,2)}$ Jurusan Teknik Sipil, Universitas Syiah Kuala \\ ${ }^{3)}$ Alumni, Jurusan Teknik Sipil, Universitas Syiah Kuala \\ Corresponding email: sugiarto@unsyiah.ac.id
}

DOI: http://dx.doi.org/10.29103/tj.v8i2.173

\begin{abstract}
Abstrak
Kapasitas jalinan sangat berperan penting untuk perencanaan bundaran lalu lintas terutama pada lalu lintas campuran dengan komposisi lalu lintas didominasi kendaraan roda dua (sepeda motor). Simpang Tujuh Ulee Kareng merupakan simpang tak bersinyal dengan kondisi lalu lintas campuran dengan proporsi roda dua sangat tinggi. Maka, penelitian ini bertujuan untuk meninjau pengaruh proporsi roda dua terhadap kapasitas bagian jalinan. Metode analisis digunakan simulasi lalu lintas dengan menggunakan simulator VISSIM 6.00-22. Lokasi penelitian dipilih Simpang Tujuh Ulee Kareng dimana berdasarkan Rencana Tata Bangunan dan Lingkungan (RTBL) Kawasan Simpang Tujuh Ulee Kareng yang direncanakan oleh pemerintah Kota Banda Aceh dengan konstruksi Bundaran.Hasil penelitian dengan menggunakan simulator lalu lintas VISSIM 6.00-22 kapasitas bagian jalinan hanya mengalami perubahan kecil pada skenario komposisi roda dua 40\% - 90\%. Penurunan kapasitas bagian jalinan terjadi saat komposisi roda dua/motorcycle (MC) pada skenario $10 \%$ $30 \%$ yang diakibatkan meningkatnya komposisi kendaraan ringan/light vehicle (LV) sehingga membuat banyaknya ruang antara (gap) kendaraan yang kosong. Panjang antrian dan tundaan yang terjadi semakin rendah saat komposisi roda dua (MC) pada skenario $40 \%$ - 90\%. Dari hasil simulasi dapat dilihat bahwa roda dua (MC) memberikan keleluasaan pada ruang jalan sehingga arus menjadi lebih lancar. Seiring meningkatnya komposisi kendaraan ringan (LV) atau roda empat mengakibatkan ruang jalan menjadi lebih sempit. Kendaraan yang berada di jalinan cukup sulit untuk bergerak sehingga kecepatan menurun yang berdampak pada antrian kendaraan yang panjang dan menyebabkan menurunnya kapasitas bagian jalinan Bundaran.
\end{abstract}

Kata kunci: Kapasitas Jalinan, Bundaran, Simulasi, VISSIM 6.00-22, Simpang Tujuh Ulee Kareng.

\begin{abstract}
Weaving capacity is vital for designing roundabout, especially in mixed traffic condition with two-wheeled vehicles are predominant. The SimpangTujuh Ulee Kareng is a type of un-signalized intersection with profoundlymixed traffic operationand an identical high proportion of two-wheelers. In this study, the influence of the proportion of two-wheelers on weaving capacity was analyzed using the VISSIM 6.00-22 traffic simulator. The study was located at the SimpangTujuh Ulee Kareng, which is selected based on the Building and Environmental Planning (RTBL) of SimpangTujuh Ulee Kareng area made by the Government of Banda Aceh and planned to be designed as Roundabout. The simulation results demonstrated that the weaving capacity has a minor change on the motorcycle (MC) compositions scenario by $40 \%-90 \%$. The decreasing of weaving capacity occurs in $10 \%-30 \%$ of the MC scenario due to increasing of light vehicle (LV) composition resulting in abundance of empty vehicle gaps. The queue length and delay occur become lower at two-wheeled composition scenario in $40 \%-90 \%$. By the simulation results can be seen that the
\end{abstract}

Pengaruh sepeda motor terhadap kapasitas bagian jalinan pada perencanaan bundaran di Simpang Tujuh Ulee Kareng - Sugiarto. S, Faisal. R, Reyhan. M 
two-wheeled (MC) gives the driver more space on the road so that the traffic flow more reliable. As the light vehicle (LV) or four-wheeled compositions increasing causes road space becomes narrower so that the vehicles which in the weaving section quite difficult to move therefore the speed decreasing which influences to the queue length of vehicle becomes long and causes the decreasing of weaving capacity of Roundabout.

Keywords: Weaving Capacity, Roundabout, Simulation, VISSIM 6.00-22, Simpang Tujuh Ulee Kareng

\section{Latar Belakang}

Kepemilikan kendaraan pribadi seperti roda dua dan mobil mengakibatkan masyarakat sangat tergantung pada kendaraan pribadi termasuk di Banda Aceh, ibu kota Provinsi Aceh. Akibatnya timbullah permasalahan atau dampak serius akibat tingginya mobilitas masyarakat dengan kendaraan pribadi, misalnya naiknya waktu tempuh perjalanan, naiknya biaya operasional kendaraan, polusi udara, kebisingan hingga kerugian ekonomi kota (Sugiarto dkk., 2017). Kemacetan menjadi isu genting di berbagai kota di Indonesia misalnya di Jakarta (Sugiarto dkk., 2014; Sugiarto $d k k ., 2017$ ), di Banda Aceh (Sofyan $d k k ., 2017$ ) dan di Lhokseumawe dengan isu kepemilikan roda dua (Anggraini $d k k$., 2017). Kemacetan lalu lintas ditinjau dari sisi mikroskopis dapat diakibatkan oleh adanya gangguan parkir dipinggir jalan, aktivitas lalu lintas pada segmen u-turn dan pada persimpangan. Pengaruh aktivitas u-turn dan parkir dipinggir jalan sangat signifikan terhadap karakteristik dan kualitas pelayanan jalan terutama pada jam puncak di Banda Aceh (Sugiarto dkk., 2012; Sugiarto $d k k$., 2013). Lalu lintas pada persimpangan memiliki karakteristik yang sangat komplek terutama pada simpang tak bersinyal dan daerah jalinan (bundaran). Sugiarto $d k k$., (2018) mempelajari karakteristik lalu lintas di Bundaran Lambaro, Aceh Besar. Mereka mengalibrasi kembali angka ekuivalensi mobil penumpang (EMP) menggunakan data okupansi yang diobservasi menggunakan drone. Mereka menyimpulkan faktor konversi EMP sangat signifikan mempengaruhi dalam analisis kapasitas dan kinerja Bundaran.

Bundaran merupakan daerah jalinan yang mampu mendistribusikan arus lalu lintas dengan volume lalu lintas rendah hingga medium. Pada kondisi arus lalu lintas medium bundaran mampu mengurangi tundaan dan memberikan pergerakan yang aman dibandingkan dengan simpang tak bersinyal. Bundaran juga dapat mengurangi potensi kecelakaan dikarenakan pergerakan kendaraan masuk ke daerah jalinan akan mengalami merging atau weaving dengan kecepatan yang relatif rendah (TroutbeckdanBrilon, 2001). Dewasa ini, bundaran banyak diaplikasikan sebagai alternatif simpang tak bersinyal hampir di berbagai negara baik dengan pengoperasian lalu lintas campuran ataupun lalu lintas homogen. Bundaran memberikan kapasitas lebih baik dibandingkan dengan simpang tak bersinyal pada kondisi volume lalu lintas rendah (Sonudkk., 2016). Pada lalu lintas homogen banyak penelitian terdahulu telah mempelajari karakteristik arus lalu lintas pada bundaran misalnya Chandra dan Kumar(2003), Lee (2015) dan Sonudkk., (2016)namun masih sangat minim studi karakteristik lalu lintas pada bundaran pada kondisi lalu lintas campuran. Kebanyakan studi terdahulu mempelajari karakteristik lalu lintas bundaran dengan mengalibrasi kembali faktor ekuivalensi mobil penumpang dan pengaruhnya pada kapasitas bundaran (Arasan 
dan Arkatkar (2010), Praveen dan Arasan (2013), Sugiarto dkk., (2018)). Maka pada penelitian ini bertujuan untuk menganalisis pengaruh komposisi roda dua terhadap kapasitas bagian jalinan pada Simpang Tujuh Ulee Kareng dengan perencanaanbundaran tipe R10-22 menggunakan simulator lalu lintas VISSIM 6.00-22.Uraian tentang metodologi pengambilan data, pengolahan data, analisis data, pembahasandan pengambilan kesimpulan disampaikan pada bab-bab selanjutnya.

\section{Metode Penelitian}

\subsection{Pengumpulan Data}

Penelitian dilakukan pada Simpang Tujuh Ulee Kareng di Kota Banda Aceh seperti yang terlihat pada Gambar 1. Data utama yang digunakan dalam analisis adalah data primer yaitu geometrik persimpangan termasuk lengan pendekat masing-masing, volume lalu lintas dan kecepatan setempat. Pengamatan dilakukan selama dua hari yaitu pada hari Senin dan Kamis, dimulai dari pagi pukul 07.00 - 09.00 WIB, dan sore pukul 16.30 - 18.30 WIB. Pada jam-jam tersebut diperkirakan terjadinya jam puncak. Data geometrik jalan yang diambil yaitu lebar jalur jalan pada semua lengan pendekat. Pengukuran geometrik jalan dilakukan oleh 2 surveyor dan dilakukan pada saat lalu lintas sepi yaitu hari Jumat sebelum waktu Shalat Jumat menggunakan alat ukur meteran.

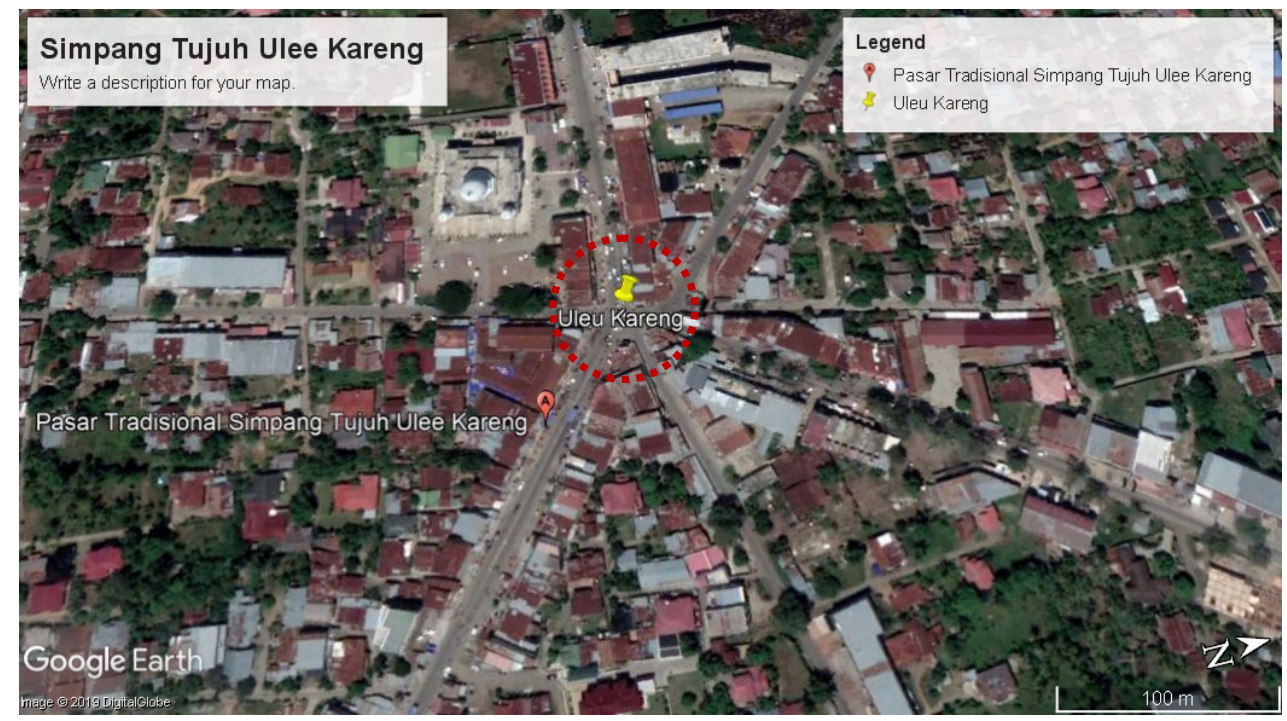

Gambar 1 Lokasi Kajian Simpang Tujuh Ulee Kareng (map data (C 2019 Google)

Pengamatan volume lalu lintas bertujuan untuk mendapatkan besarnya volume, komposisi lalu lintas, dan sebaran kendaraan pada Simpang Tujuh Ulee Kareng. Pengamatan dilakukan pada waktu pagi pukul $07.00-09.00$ WIB dan sore pukul 16.30 - 18.30 WIB karena pada wilayah tersebut terdapat Pasar Ulee Kareng, warung kopi, kedai makanan, pedagang kaki lima dan lain-lain yang aktivitasnya tinggi pada pagi dan sore hari. Pengamatan dilakukan oleh 3 orang surveyor dengan cara merekam setiap jenis kendaraan yang melewati Simpang Tujuh Ulee Kareng dari tiap lengan simpang ke lengan-lengan simpang lainnya. Data volume lalu lintas yang digunakan adalah volume lalu lintas puncak pada

Pengaruh sepeda motor terhadap kapasitas bagian jalinan pada perencanaan bundaran di Simpang Tujuh Ulee Kareng - Sugiarto. S, Faisal. R, Reyhan. M 
hari pengamatan selama dua hari dengan interval waktu 15 menit. Pengamatan volume dan komposisi lalu lintas yang melintasi jalan tersebut dibedakan atas beberapa jenis kendaraan yaitu 1) kendaraan ringan/Light Vehicle (LV) seperti: mobil penumpang, L300 dan pickup; 2) Kendaraan berat/HeavyVehicle (HV) seperti: bus dan truk; dan 3) Sepeda Motor/Motorcycle (MC) seperti sepeda motor dan becak.

Kecepatan yang diamati pada studi kasus ini untuk jalan per satu arah adalah kecepatan setempat. Pengamatan kecepatan dilakukan dengan menggunakan alat speed gun. Cara kerja speed gun berdasarkan efek dopler, dimana alat tersebut memancarkan suatu gelombang radar yang diarahkan pada suatu objek yang bergerak (mobil) dan dipantulkan kembali ke alat untuk kemudian oleh perangkat ini diukur kecepatan objek tersebut. Data kecepatan diamati pada tiap jalur saat kendaraan menuju dan keluar dari persimpangan. Sampel yang diambil sebanyak 60 (enam puluh) kendaraan dari setiap jenis kendaraan.

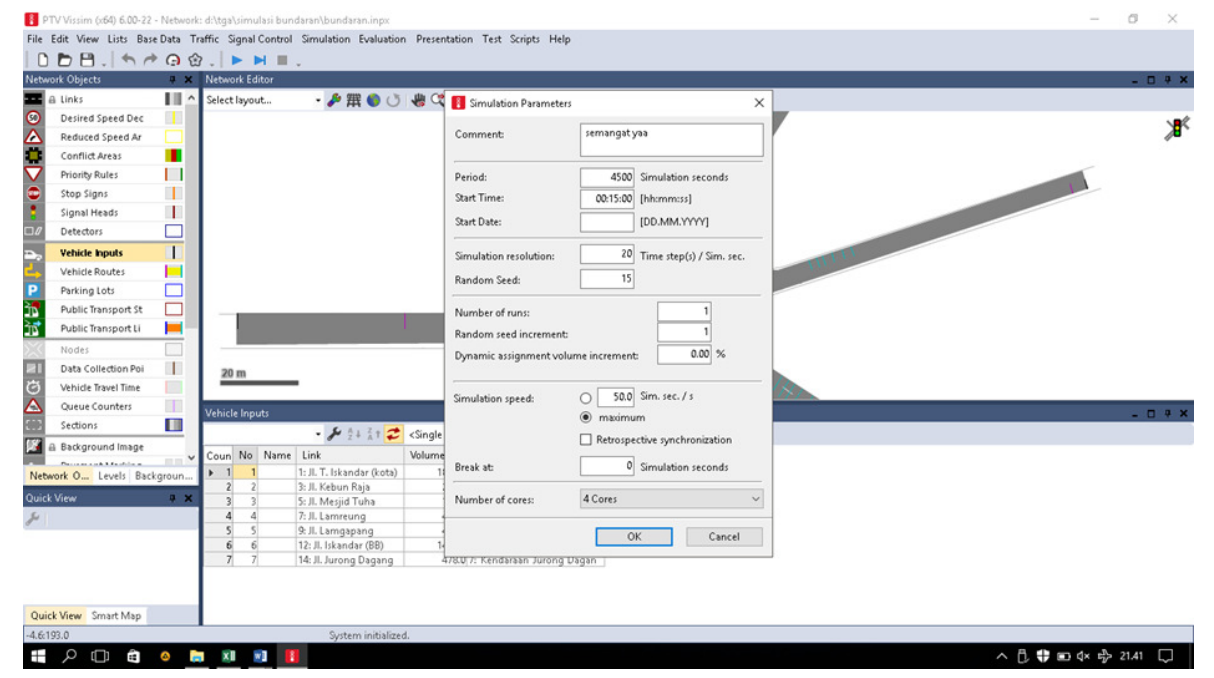

Gambar 2 Proses pengaturan simulasi (input randomseed dan simulationrun)

\subsection{Analisis dan Pemodelan VISSIM}

Pengolahan data dilakukan setelah data-data hasil pengamatan di lapangan telah direkapitulasi sehingga data tersebut dapat dianalisis dan dapat disimulasikan dengan menggunakan VISSIM 6.00-22. Berikut ini adalah tahapantahapan pemodelan prototipe VISSIM 6.00-22 untuk menjalankan simulasi dan mendapat video visualisasi aliran lalu lintas, yaitu 1) menginputlatar (background); 2) pembentukan jaringan jalan (networkcoding); 3) membangun ruas penghubung (link-connectors); 4) menentukan jumlah kendaraan (vehicle input); 5) menginput kecepatan kendaraan (desiredspeed); 6) menginput komposisi kendaraan (vehiclecomposition); 7) menentukan rute perjalanan (vehicleroute); 8) menginput komposisi rute perjalanan; 9) melakukan kalibrasi (drivingbehaviorcalibration); 10) pengaturan jumlah trial simulasi (rundomseeds\&simulationruns); 11) menjalankan simulasi (simulationruns) dan 12) penentuan parameter kinerja (measurement of effectiveness). Untuk menjalankan simulasi prosedur 1-10 diatas harus sudah selesai dikerjakan. Sebagai tahap awal parameter kalibrasi dalam model VISSIM 6.00-22 yang 
dipilih termasuk mobil dan perubahan jalur. Berikut ini parameter untuk menjalankan model simulasi yaitu periode/lama waktu simulasi, waktu mulai, tanggal mulai, resolusi simulasi, random seed dan berhenti/selesai. Bentuk tampilan pengaturan sebelum menjalankan simulasi dapat dilihat pada Gambar 2.

\section{Hasil dan Pembahasan}

\subsection{Geometrik Jalan dan Penentuan Tipe Bundaran}

Tabel 1 memperlihatkan geometrik masing-masing lengan pendekat beserta informasi lebar jalur dan tipe jalan masing-masing lengan pendekat. Ukuran bundaran ditentukan berdasarkan ukuran kota dan volume jam puncak dari salah satu lengan pendekat yaitu Jalan T. Iskandar (Arah Pusat Kota Banda Aceh) menggunakan MKJI (1997) sehingga didapatkan tipe bundaran R10-22, dengan lebar jalinan 9 meter ditambah lebar apron 2 meter untuk kendaraan berat (HV) seperti yang terlihat pada Gambar 3.

Tabel 1 Tipe jalan dan lebar jalur masing-masing pendekat simpang

\begin{tabular}{llrc}
\hline No. & Ruas Jalan & $\begin{array}{c}\text { Lebar } \\
\text { Lajur }\end{array}$ & $\begin{array}{l}\text { Jumlah } \\
\text { Lajur }\end{array}$ \\
\hline 1. & Jalan T. Iskandar (Arah Pusat Kota Banda Aceh) & $8 \mathrm{~m}$ & $4 / 2 \mathrm{UD}$ \\
\hline 2. & Jalan Kebun Raja & $6 \mathrm{~m}$ & $2 / 2 \mathrm{UD}$ \\
\hline 3. & Jalan Mesjid Tuha & $4 \mathrm{~m}$ & $2 / 2 \mathrm{UD}$ \\
\hline 4. & Jalan Lamreung & $6 \mathrm{~m}$ & $2 / 2 \mathrm{UD}$ \\
\hline 5. & Jalan Lamgapang & $5 \mathrm{~m}$ & $2 / 2 \mathrm{UD}$ \\
\hline 6. & Jalan T. Iskandar (Arah Blang Bintang) & $10 \mathrm{~m}$ & 4/2D \\
\hline 7. & Jalan Jurong Dagang & $5 \mathrm{~m}$ & $2 / 2 \mathrm{UD}$ \\
\hline
\end{tabular}

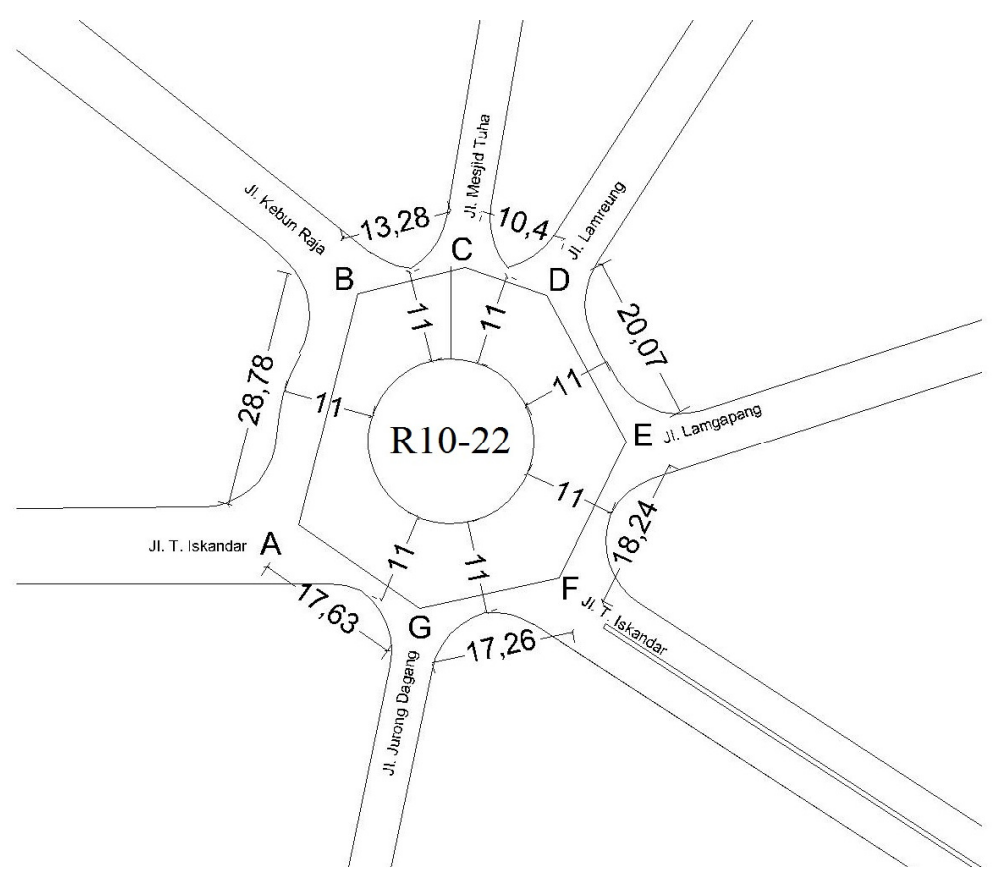

Gambar 3 Rencana geometrik bundaran dengan tipe R10-22

Pengaruh sepeda motor terhadap kapasitas bagian jalinan pada perencanaan bundaran di Simpang Tujuh Ulee Kareng - Sugiarto. S, Faisal. R, Reyhan. M 


\subsection{Volume Jam Puncak dan Kecepatan Setempat}

Data volume lalu lintas diperoleh dengan mencatat semua jenis kendaraan yang melintasi titik pias pengamatan dalam interval waktu 15 menit kemudian diolah menjadi volume lalu lintas dalam interval waktu satu jam. Berdasarkan volume lalu lintas yang diperoleh dari lokasi penelitian, diambil volume jam puncak (VJP) dengan interval waktu satu jam sebagai data masukan untuk proses simulasi menggunakan VISSIM 6.00-22.Rekapitulasi perhitungan VJP dari volume lalu lintas dapat dilihat pada Tabel 2.

Tabel 2Rekapitulasi volume jam puncak

\begin{tabular}{clc}
\hline No & \multicolumn{1}{c}{ Lengan Pendekat } & $\begin{array}{c}\text { VJP } \\
\text { (kend./jam) }\end{array}$ \\
\hline 1. & Jalan T. Iskandar (Arah Pusat Kota Banda Aceh) & 1.861 \\
\hline 2. & Jalan Kebun Raja & 290 \\
\hline 3. & Jalan Mesjid Tuha & 176 \\
\hline 4. & Jalan Lamreung & 407 \\
\hline 5. & Jalan Lamgapang & 430 \\
\hline 6. & Jalan T. Iskandar (Arah Blang Bintang) & 1.440 \\
\hline 7. & Jalan Jurong Dagang & 478 \\
\hline
\end{tabular}

Kecepatan setempat didapat dengan menggunakan speedgun, dengan jarak pengambilan $25 \mathrm{~m}$ dari persimpangan.Rekapitulasi perhitungan kecepatan setempat dapat dilihat pada Tabel 3.

Tabel 3Rekapitulasi kecepatan setempat

\begin{tabular}{clc}
\hline No & \multicolumn{1}{c}{ Lengan Pendekat } & $\begin{array}{c}\text { Kecepatan } \\
\text { (Km/jam) }\end{array}$ \\
\hline 1. & Jalan T. Iskandar (Arah Pusat Kota Banda Aceh) & 14,60 \\
\hline 2. & Jalan Kebun Raja & 22,34 \\
\hline 3. & Jalan Mesjid Tuha & 20,80 \\
\hline 4. & Jalan Lamreung & 23,47 \\
\hline 5. & Jalan Lamgapang & 22,06 \\
\hline 6. & Jalan T. Iskandar (Arah Blang Bintang) & 19,94 \\
\hline 7. & Jalan Jurong Dagang & 20,98 \\
\hline
\end{tabular}

\subsection{Hasil Simulasi}

Hasil dari simulasi lalu lintas dengan menggunakan VISSIM 6.00-22 denganpenggandaan randomseed sebanyak 15 kali dan melakukan simulationrunsebanyak 10 kali rekapitulasi pengukuran kinerja lalu lintas pada Bundaran Simpang Tujuh Ulee Kareng dapat dilihat pada Tabel 3. Dari Tabel 3 didapatkan hasil berupa panjang antrian maksimum (QLenMax), distribusi kendaraan atau volume (FlowAll), tundaan rata-rata kendaraan (VehDelayAll), dan kapasitas (Capacity). Kapasitas didapatkan dengan menghitung nilai kumulatif $90 \%$ dari volume sehingga didapat kapasitas dinamis (Chang $d k k$., 2000). Grafik hubungan komposisi roda dua terhadap panjang antrian dapat dilihat pada Gambar 4. Untuk kapasitas bagian jalinan selengkapnya dapat dilihat pada Gambar 5. 
Tabel 3 Rekapitulasi hasil simulasi VISSIM 6.00-22

\begin{tabular}{ccccc}
\hline $\begin{array}{c}\text { Komposisi } \\
\text { Roda Dua } \\
(\boldsymbol{\%})\end{array}$ & $\begin{array}{c}\text { QLenMax } \\
(\mathbf{m})\end{array}$ & $\begin{array}{c}\text { Flow } \\
(\mathbf{A l l})(\mathbf{v p h})\end{array}$ & $\begin{array}{c}\text { Veh } \\
\text { Delay } \\
(\mathbf{A l l})(\mathbf{s})\end{array}$ & $\begin{array}{c}\text { Capacity* } \\
(\mathbf{v p h})\end{array}$ \\
\hline 10 & 33,42 & 2.844 & 3,06 & 2.855 \\
\hline 20 & 21,79 & 2.971 & 2,3 & 2.997 \\
\hline 30 & 14,64 & 3.102 & 1,93 & 3.130 \\
\hline 40 & 11,86 & 3.154 & 1,57 & 3.195 \\
\hline 50 & 9,50 & 3.153 & 1,31 & 3.196 \\
\hline 60 & 8,30 & 3.155 & 1,01 & 3.199 \\
\hline 70 & 8,17 & 3.155 & 0,83 & 3.203 \\
\hline 80 & 6,83 & 3.156 & 0,57 & 3.201 \\
\hline 90 & 6,22 & 3.156 & 0,38 & 3.202 \\
\hline$*$ pada 90 persentilkumulatif & & &
\end{tabular}

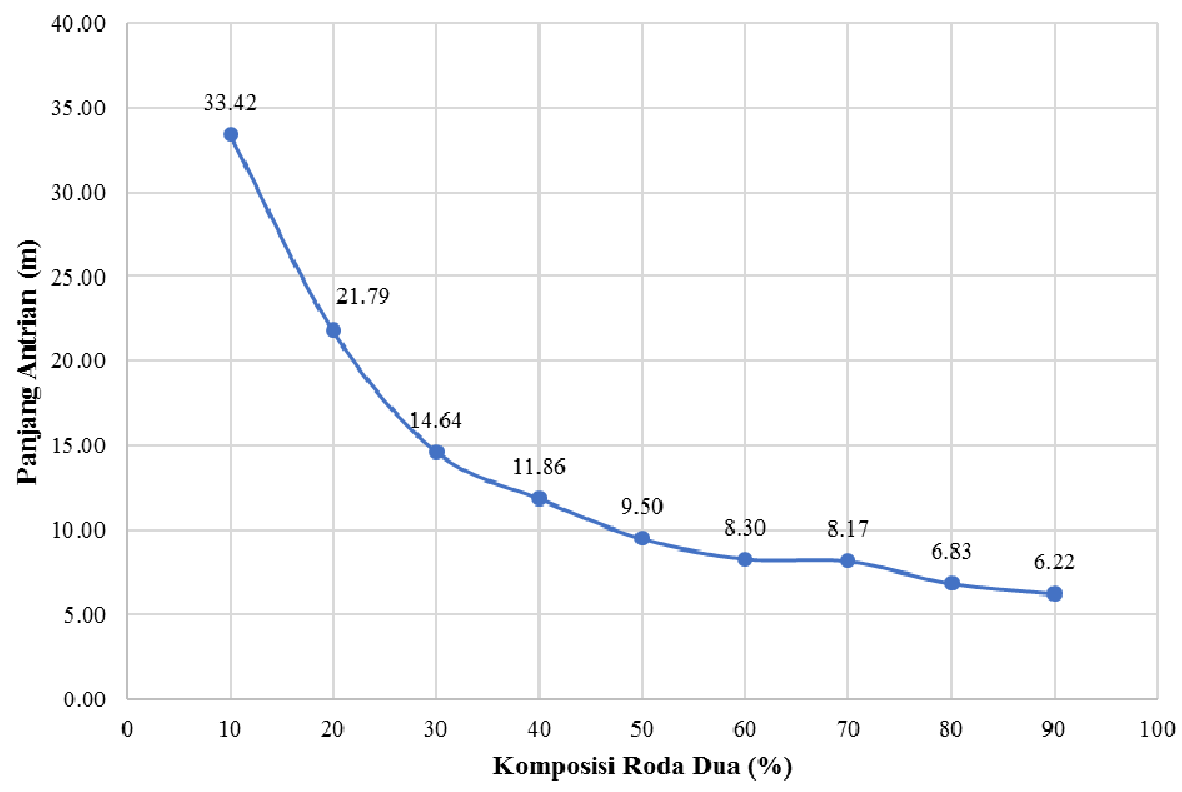

Gambar 4Hubungan komposisi Roda Dua terhadap panjang antrian

Dari Gambar 4 dapat dilihat penurunan curam pada skenario komposisi roda dua (MC) $10 \%$ - 30\%. Namun, penurunan semakin landai pada skenario $40 \%$ 90\%. Hal ini disebabkan oleh ukuran geometrik yang masih mampu mendistribusikan arus kendaraan.Sama halnya seperti pada panjang antrian, pergerakan grafik yang terlihat curam pada skenario $10 \%-30 \%$ namun stabil pada skenario 40\%-90\% disebabkan oleh ukuran geometrik yang masih mampu menampung volume kendaraan.Sedangkan untuk tundaan, pada Tabel 4 diuraikan penurunan tundaan pada skenario 40\% - 90\% karena kapasitas pada skenario tersebut terlihat stabil. Rata-rata dari tundaan pada skenario $40 \%-90 \%$ sebesar 0,95 detik. 


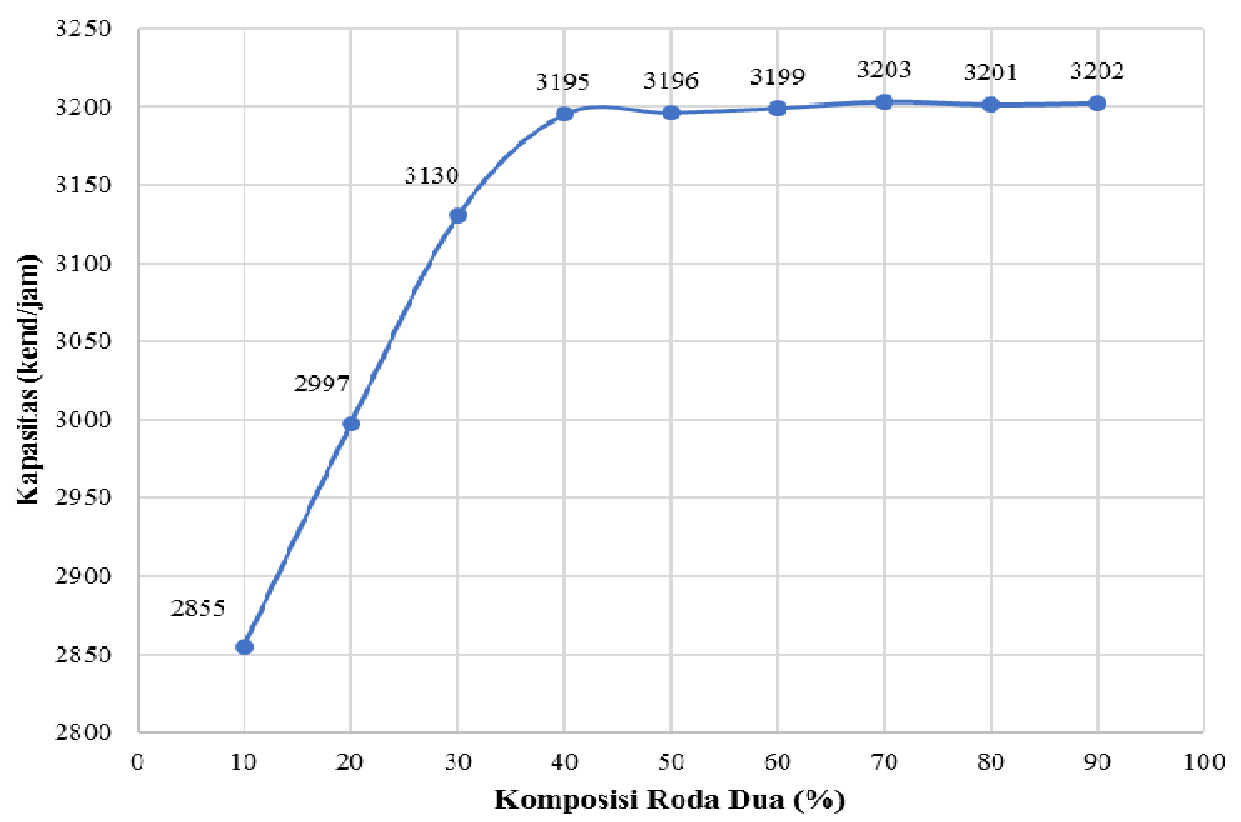

Gambar 5 Hubungan komposisi Roda Dua terhadap Kapasitas Jalinan

Tabel 4Tundaan kendaraan pada bagian jalinan

\begin{tabular}{cccc} 
No. & $\begin{array}{c}\text { Skenario Komposisi Roda } \\
\text { Dua (MC) }\end{array}$ & $\begin{array}{c}\text { Kapasitas } \\
\text { (kend/jam) }\end{array}$ & $\begin{array}{c}\text { Tundaan } \\
\text { (detik) }\end{array}$ \\
\hline 1. & $40 \%$ & 3.195 & 1,57 \\
\hline 2. & $50 \%$ & 3.196 & 1,31 \\
\hline 3. & $60 \%$ & 3.199 & 1,01 \\
\hline 4. & $70 \%$ & 3.203 & 0,83 \\
\hline 5. & $80 \%$ & 3.201 & 0,57 \\
\hline 6. & $90 \%$ & 3.202 & 0,38 \\
\hline & & Rata-rata & $\mathbf{0 , 9 5}$ \\
\hline
\end{tabular}

\subsection{Pembahasan}

Hasil simulasi yang dilakukan pada Simpang Tujuh Ulee Kareng menggunakan VISSIM 6.00-22, menampilkan distribusi kendaraan atau volume sebagai hasil dari node yang dipasang pada bagian jalinan bundaran. distribusi kendaraan di bagian jalinan dari hasil simulasi dijadikan sebagai kapasitas bagian jalinan dengan menggunakan $90 \%$ nilai kumulatif dari 10 kali simulationrun sebagai nilai yang mewakili tiap satu skenario dari sembilan skenario yaitu, kondisi eksisting dengan komposisi roda dua 80\%, 90\%, 70\%, 60\%, 50\%, 40\%, $30 \%, 20 \%$ dan $10 \%$.

Dari grafik hasil simulasi dapat dilihat bahwa kapasitas bagian jalinan semakin menurun saat komposisi roda dua dikurangi. Pada skenario 40\% - 90\% atau pada kondisi oversaturated roda dua, terlihat kapasitas tidak berubah signifikan. Hal tersebut diakibatkan oleh ukuran geometrik bundaran yang direncanakan masih sangat leluasa bagi kendaraan untuk bermanuver. Menurut Peraturan Menteri Perhubungan Nomor: KM 14 Tahun 2006 Halaman 21, 
tundaan yang didapat dari simulasi VISSIM 6.00-22 masuk dalam kategori tingkat pelayanan A, yaitu kurang dari 5 detik.

\section{Kesimpulan dan Saran \\ 4.1 Kesimpulan}

Adapun beberapa kesimpulan yang dapat diambil berdasarkan analisis yang dilakukan pada penelitian ini dengan menggunakan VISSIM 6.00-22secara rinci sebagai berikut:

1. Kapasitas bagian jalinan hanya mengalami perubahan kecil pada skenario komposisi roda dua (MC) 40\% - 90\%. Penurunan kapasitas bagian jalinan terjadi saat komposisi roda dua (MC) pada skenario 10\% - 30\% yang diakibatkan meningkatnya komposisi kendaraan ringan (LV) sehingga membuat banyaknya ruang antara (gap) kendaraan yang kosong.

2. Panjang antrian dan tundaan yang terjadi semakin rendah saat komposisi roda dua (MC) pada skenario $40 \%-90 \%$.

Dari hasil simulasi yang telah dilakukan dapat dilihat bahwa pengaruh komposisi roda dua (MC) sangat berdampak bagi kelancaran arus lalu lintas di bagian jalinan. Kecilnya dimensi kendaraan roda dua (MC) memberikan kemudahan untuk bermanuver dan bergerak. Seiring meningkatnya komposisi kendaraan ringan (LV) atau roda empat mengakibatkan ruang jalan menjadi lebih sempit sehingga kendaraan yang berada di jalinan cukup sulit untuk bergerak sehingga kecepatan menurun yang berdampak pada antrian kendaraan yang panjang dan menyebabkan menurunnya kapasitas bagian jalinan bundaran.

\subsection{Saran}

Penanganan kemacetan lalu lintas yang direncanakan dan dimuat dalam dokumen RTBL oleh pemerintah Aceh sudah memenuhi kriteria kinerja lalu lintas berdasarkan analisis dengan VISSIM. Maka bundaran dengan tipe R10-22 dapat digunakan sebagai tipe bundaran yang sesuai dengan kondisi lalu lintas pada tahun 2018. Untuk keberlanjutan kapasitas bundaran masih perlu dilakukan prediksi lalu lintas dalam beberapa tahun ke depan dan pada penelitian ini tidak mengakomodir isu pertumbuhan lalu lintas sehingga direkomendasikan untuk penelitian selanjutnya.

\section{Daftar Kepustakaan}

Anonim, 1997. Manual Kapasitas Jalan Indonesia (MKJI), Direktorat Jenderal Bina Marga, Departemen Pekerjaan Umum, Jakarta.

Aggraini, R., Sugiarto, S., Pramanda, H., 2017. Factor saffecting trip generation of motor cyclist for the purpose of non-mandatory activities. AIP Conf. Proc, vol. 1903, 060011.

Arasan, V. T., Arkatkar, S. S., 2010. Micro-simulation study ofeffectof volume and road width on pcu of vehicles under heterogeneous traffic. Journal of Transportation Engineering, 136(12), 1110-1119.

Chandra, S., Kumar, U., 2003. Effectof lane width on capacity under mixed traffc conditions in India. Journal of Transportation Engineering, 129(2), 155160.

Pengaruh sepeda motor terhadap kapasitas bagian jalinan pada perencanaan bundaran di Simpang Tujuh Ulee Kareng - Sugiarto. S, Faisal. R, Reyhan. M 
Lee, C., 2015. Developing passenger-car equivalents for heavy vehicles in entry fowat round abouts. Journal of Transportation Engineering, 141(8), 04015013.

Chang, M., Kim, Y., 2000, Development of capacity estimation method from statistical distribution of observed traffic flow. Proceedings: Fourth International Symposiumon Highway Capacity, pp. 299-309.

Praveen, P. S., Arasan, V. T., 2013. Influence of traffc mix on pcu value of vehicles under heterogeneous traffc conditions. International Journal for Traffic and Transport Engineering, 3(3), pp. 302-330.

Saleh, S.M., Sugiarto, S., Hilal, A., Ariansyah, D., 2017. A study on the traffic impact of the road corridors due to fly over construction at surabaya intersection, Banda Aceh of Indonesia. AIP Conference Proceedings 1903, 060005.

Sonu, M., Dhamaniya, Ashish., Shriniwas., Joshi, Gaurang. 2016. Time occupancy as measure of pcu at four legged round abouts. Transportation Letters: the International Journal of Transportation Research. Online First.

Sugiarto, Limanond, T. And Nakatsuji, T., 2012. Dropped in capacity and traffic speed of urban Arterial: a case study at u-turn section in Aceh Province, Indonesia. Aceh International JournalofScienceand Technology, (3), pp. 86-92.

Sugiarto, S., Limanond, T., 2013. Impact of on-streetparking on urban arterial performance: A quantitative study on travel speed and capacity deterioration. Aceh International Journal of Scienceand Technology, 2(1), pp. 63-69.

Sugiarto, S., Miwa, T., Sato, H., Morikawa, T., 2014. Congestion charging: Influence of public consciousness on acceptability in Jakarta Metropolitan Area. Proceedings of 21st World Congress on Intelligent Transport Systems, Detroit, USA.

Sugiarto, S., Miwa, T., Sato, H., Morikawa, T., 2017. Explaining differences in acceptance determinants towards congestion charging policies in Indonesia and Japan. Journal of Urban Planning and Development (ASCE), 143(2): $1-12$.

Sugiarto, S., Apriandy, F., Faisal, R., Saleh, S.M., 2018. Measuring Passenger Car Unit at Four-Legged Round about using Time Occupancy Data Collected from Drone. Aceh International Journal of Scienceand Technology, 7(2), pp. 77-84.

Troutbeck R., Brilon W., 2001. Unsignalised Intersection Theory Chapter 8, Traffc Flow Theory, A State-of-the-Art Report, Organized by the Committeeon Traffc Flow Theory and Characteristics. 